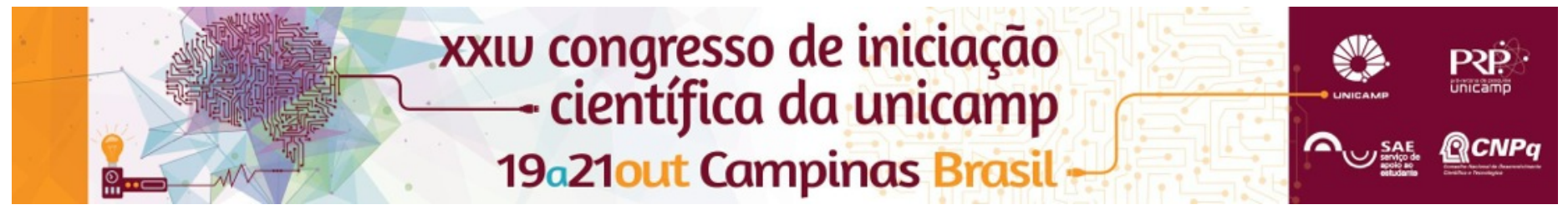

\title{
ASPECTOS LINGUÍSTICOS-COGNITIVOS, PARTICIPAÇÃO E USO DE DISPOSITIVOS DE COMUNICAÇÃO ALTERNATIVA SUPLEMENTAR EM AFÁSICOS
}

\author{
Verônica B. Padovan*, Regina Yu Shon Chun - Curso de Fonoaudiologia, DDHR/CEPRE/FCM - UNICAMP
}

\section{RESUMO}

A pessoa com afasia pode necessitar de recursos que favoreçam sua linguagem, tais como a Comunicação Suplementar e/ou Alternativa (CSA) pode proporcionar. Para descrever diferentes condições de saúde de forma positiva, foi criada a Classificação Internacional de Incapacidade, Funcionalidade e Saúde (CIF) pela OMS. O objetivo é investigar aspectos de linguagem, participação e uso de dispositivos de CSA em afásicos utilizando-se a CIF como base conceitual. A amostra se constitui de 3 afásicos usuários de CSA. Os resultados mostram o impacto da afasia na vida dessas pessoas e a repercussão do processo terapeutico e do uso da CSA. Reafirmam a CSA como facilitadora da comunicação, assim como o uso da CIF para análise dos aspectos de participação e funcionalidade.

Palavras-chave: Afasia, CIF, barreiras de comunicação

\section{INTRODUÇÃO}

A afasia, comprometimento da linguagem em graus e tipos variados, é uma das sequelas de um acidente vascular cerebral (AVC). Implica diferentes recursos de assistencia à saúde, tais como a Comunicação Suplementar e/ou Alternativa (CSA) pode proporcionar para favorecer a linguagem (Chun, 2010 e 2013). A fim de retratar diferentes condições de saúde, em uma perspectiva positiva de saúde, foi desenvolvida pela Organização Mundial de Saúde (OMS) a CIF - Classificação Internacional de Incapacidade, Funcionalidade e Saúde. O objetivo é investigar aspectos de linguagem, participação e uso da CSA em afásicos utilizando-se a CIF como base conceitual.

\section{RESULTADOS E DISCUSSÃO}

A amostra se constitui de 3 afásicos usuários de CSA. A coleta se deu pelo levantamento do prontuário para caracterização do perfil sociodemográfico e de registros em vídeo do acompanhamento fonoaudiológico. Foram transcritos e analisados episódios linguísticos relevantes aos objetivos utilizando-se a CIF para análise. A CIF apresenta três componentes: (i) corpo, (ii) atividade e participação e (iii) contexto, que englobam diferentes domínios, correspondendo a diferentes códigos, como por exemplo b1672 - funções da linguagem. Cada qualificador indica um grau de gravidade ou de extensão do problema (CCOMS, 2003). Utilizou-se dominios da CIF de outro estudo (Dallaqua e Chun, 2015).

Dos registros em vídeo, observa-se evolução dos participantes nos aspectos linguísticos-cognitivos, expresso em domínios da CIF tais como recepção de mensagens não verbais - d315 e expressão da linguagem e uso da CSA como facilitador no item produtos e tecnologia de comunicação - e125. Os participantes utilizam diversas formas de comunicação, sejam os recursos de CSA, gestos próprios, expressão facial e/ou, produção oral, utilizando processos alternativos de significação (Coudry, 2002 e Chun, 2010)

Verifica-se, ao longo do período estudado, que os dispositivos de CSA, como as pranchas de comunicação e outras atividades possibilitaram aos participantes, melhor expressão de suas necessidades e desejos, beneficiando também suas famílias, com uma comunicação mais eficiente. Achados encontrados por outros autores, como Bahia e Chun (2014). Os resultados evidenciam que a intervenção terapêutica favorece a linguagem dos afásicos e consequentemente, a interação e participação social da pessoa com afasia. Reafirmam a utilidade da CIF para análise das repercussões da linguagem na participação e funcionalidade do grupo estudado.

\section{CONCLUSÕES}

Os resultados reiteram o uso da CSA como facilitadora da comunicação nos âmbitos familiar e terapêutico, assim como a aplicabilidade da CIF como base conceitual nos estudos clínicos da afasia. Os achados mostram que analisar a linguagem e o uso da CSA tomando a CIF como base conceitual traz um novo olhar quanto as condições linguístico-cognitivas, possibilita a incorporação de aspectos de participação e funcionalidade da pessoa com afasia e contribui para se pensar a atenção à saúde desse grupo populacional, para além da dimensão orgânica, isto é, de forma integral.

\section{AGRADECIMENTOS}

Aos participantes da pesquisa e ao PIBIC/SAE/ UNICAMP pelo auxílio recebido.

\section{REFERENCIAS BIBLIOGRÁFICAS}

BAHIA MM, CHUN RYS. Repercussão da Comunicação Suplementar e/ ou Alternativa na Afasia Não Fluente. Rev. CEFAC. 2014;16(1):147-160. CCOMS - Centro Colaborador da Organização Mundial da Saúde para a Família de Classificações Internacionais. CIF: Classificação Internacional de Funcionalidade, Incapacidade e Saúde. Trad. Cassia Maria Buchalla. São Paulo: EDUSP - Editora da Universidade de São Paulo; 2003.

CHUN RYS. Processos de significação de afásicos usuários de comunicação suplementar e/ou alternativa. Rev Soc Bras Fonoaudiol. 2010;15(4):598-603.

CHUN RYS. Linguagem e Comunicação Suplementar e/ou Alternativa: aproximações culturais, conceituais e funcionais em grupo de adultos afásicos. In: PASSERINO L et al (org). Comunicar Para Incluir. $1^{\text {a }}$ edição. Porto Alegre: CRBF, 2013. p. 343- 349.

COUDRY, M.I.H. Linguagem e Afasia: Uma abordagem discursiva da Neurolinguística. Cadernos de Estudos Linguísticos, 42, Campinas, IEL, UNICAMP, 2002.p 99-129

DALLAQUA GB, CHUN RYS. Plano Terapeutico Fonoaudiológico norteado pela CIF para afásicos utilizando a CSA. In: Pró-Fono (organizadora) Planos Terapeuticos Fonoaudiológicos (PTFs) Volume 2. Barueria,São Paulo: Pró-Fono, 2015, pp.131-138 